\title{
Effect of Insulin on System A Amino Acid Transport in Human Skeletal Muscle
}

\author{
Riccardo C. Bonadonna, Maria Pia Saccomani, * Claudio Cobelli, * and Ralph A. Defronzo
}

Metabolism Unit of the C.N.R. Institute of Clinical Physiology at the University of Pisa, 56100 Pisa, Italy; ${ }^{*}$ Department of Electronics and Informatics, University of Padova, 35131 Padova, Italy; Division of Diabetes, University of Texas Health Science Center, and Audie L. Murphy Veterans Administration Hospital, San Antonio, Texas 78284

\begin{abstract}
Transmembrane transport of neutral amino acids in skeletal muscle is mediated by at least four different systems (system $A, A S C, L$, and $N^{m}$ ), and may be an important target for insulin's effects on amino acid and protein metabolism. We have measured net amino acid exchanges and fractional rates of inward $\left(k_{\text {in }}, \min ^{-1}\right)$ and outward $\left(k_{\text {out }}, \min ^{-1}\right)$ transmembrane transport of 2-methylaminoisobutyric acid (MeAIB, a nonmetabolizable amino acid analogue, specific for system $A$ amino acid transport) in forearm deep tissues (skeletal muscle), by combining the forearm perfusion technique and a novel dual tracer $\left(\left[1-\mathrm{H}^{3}\right]-\mathrm{D}-\right.$-mannitol and $2-\left[1-{ }^{14} \mathrm{C}\right]-$ methylaminoisobutyric acid ) approach for measuring in vivo the activity of system A amino acid transport. Seven healthy lean subjects were studied. After a baseline period, insulin was infused into the brachial artery to achieve local physiologic hyperinsulinemia $(76 \pm 8 \mu \mathrm{U} / \mathrm{ml}$ vs $6.4 \pm 1.6 \mu \mathrm{U} / \mathrm{ml}$ in the basal period, $P<0.01$ ) without affecting systemic hormone and substrate concentrations. Insulin switched forearm amino acid exchange from a net output $(-2,630 \pm 1,100 \mathrm{nmol} / \mathrm{min}$ per $\mathrm{kg}$ of forearm tissue ) to a net uptake $(1,610 \pm 600 \mathrm{nmol} / \mathrm{min}$ per $\mathrm{kg}, P<0.01$ vs baseline). Phenylalanine and tyrosine balances simultaneously shifted from a net output $(-146 \pm 47$ and $-173 \pm 34 \mathrm{nmol} / \mathrm{min}$ per $\mathrm{kg}$, respectively) to a zero balance $(16.3 \pm 51$ for phenylalanine and $15.5 \pm 14.3 \mathrm{nmol} / \mathrm{min}$ per $\mathrm{kg}$ for tyrosine, $P<0.01 \mathrm{vs}$ baseline for both), showing that protein synthesis and breakdown were in equilibrium during hyperinsulinemia. Net negative balances of alanine, methionine, glycine, threonine and asparagine (typical substrates for system $A$ amino acid transport) also were decreased by insulin, whereas serine (another substrate for system $A$ transport) shifted from a zero balance to net uptake. Insulin increased $\boldsymbol{k}_{\ln }$ of MeAIB from a basal value of $11.8 \cdot 10^{-2} \pm 1.7 \cdot 10^{-2} \cdot \mathrm{min}^{-1}$ to $13.7 \cdot 10^{-2} \pm 2.2 \cdot 10^{-2}$. $\min ^{-1}(P<0.02$ vs the postabsorptive value $)$, whereas $k_{\text {out }}$ was unchanged. We conclude that physiologic hyperinsulinemia stimulates the activity of system $A$ amino acid transport in human skeletal muscle, and that this effect may play a role in determining the overall concomitant response of muscle amino acid/protein metabolism to insulin. (J. Clin. Invest. 1993. 91:514-521.) Key words: limb balance $\bullet 2$-methylaminoisobutyric acid • first-pass kinetics • protein turnover
\end{abstract}

Address correspondence to Riccardo C. Bonadonna, Istituto di Fisiologia Clinica-C.N.R., Via Savi, 8, 56100 Pisa, Italy.

Received for publication 10 December 1991 and in revised form 14 September 1992.

The Journal of Clinical Investigation, Inc.

Volume 91, February 1993, 514-521

\section{Introduction}

Elucidation of the mechanisms underlying the ability of insulin to promote an anabolic effect on protein metabolism in man has been the focus of a number of recently published studies (1-8). A large body of evidence has indicated that a major site of insulin action, as investigated by isotope techniques, is the inhibition of proteolysis (1-6, 8-12). Physiologic hyperinsulinemia has been shown to diminish protein degradation, both at the whole body level $(1-6,8-12)$ and in skeletal muscle (13-16). Although insulin has been shown to augment protein synthesis in vitro (17-22), a similar anabolic effect in vivo has been difficult to demonstrate (1-16). With regard to this apparent discrepancy, by infusing tracer amino acids in vivo, one usually yields an estimate of bulk protein synthesis both at the whole body and at the regional level. Recent data suggest that insulin, while not affecting bulk protein synthesis in vivo, may exert opposite effects on the synthetic rates of different proteins in the body (23).

Transmembrane transport of amino acids may play an important role in regulating protein balance in skeletal muscle (24-25). This is suggested by several observations. First, in the postabsorptive state most amino acids are concentrated in the intracellular compartment against their electrochemical gradient $(7,24,25)$. This phenomenon implies the operation of transport systems that actively maintain a transmembrane gradient. Second, insulin and other hormones (24) in vitro have been shown to enhance the translocation of some amino acids into the cell and an increase in intracellular amino concentration is known to stimulate protein synthesis $(13,26)$.

At least four distinct transport systems named systems A, ASC, L, and $\mathrm{N}^{\mathrm{m}}$, respectively, mediate the transmembrane traffic of neutral amino acids $(24,25,27,28)$. This definition of the amino acid transport systems is operational, inasmuch as it is based on the unique kinetic characteristics displayed by the transport of nonmetabolizable amino acid analogues across the cell membrane in in vitro systems $(24,25)$. While awaiting that the molecular identification of the carriers involved in the traffic of analogues and naturally occurring amino acids across the plasma membrane is achieved, this conventional nomenclature is a conceptual and semantic frame by which researchers denote those components of amino acid transport that are inhibitable with and probed by analogues and/or naturally occurring substrates characterized by strict specificity for a single transport system.

Systems A, ASC, and $\mathrm{N}^{\mathrm{m}}$ are sodium dependent and maintain steep transmembrane gradients in amino acid concentrations. In contrast, system L does not require sodium to operate. All these systems display partial but not absolute specificity for their substrates. On practical grounds, this means that the transmembrane traffic of, say, methionine is simultaneously 
mediated by system A and system L, each of which is independently regulated $(24,25)$. Therefore, most amino acids are transported by more than one system and, conversely, each transport system carries many an amino acid with overlapping specificity. Since the transmembrane traffic of any single amino acid is mediated by more than one transport system and is further complicated by intracellular metabolism, the most straightforward way to investigate the activity of the various amino acid transport agencies is to measure the transmembrane transport of nonmetabolizable amino acid analogues strictly specific for the transport system of interest. Of such analogues, those which are believed to display the most stringent specificity are 2-methylaminoisobutyric acid (MeAIB) ${ }^{1}$ for system $A$ and 2-(-)-endoamino-bicycloheptane-2-carboxylic acid for system $L(24,25)$. Since system $A$ is known to be hormone sensitive $(24,28)$, it seemed to us that in an attempt to elucidate the involvement of transmembrane transport in insulin action upon amino acid and protein metabolism of skeletal muscle in vivo, one should examine first the response of system A to insulin. However, no techniques are currently available to assess the activity in vivo of transmembrane amino acid transport.

Recently, we developed a method to quantitate the activity of transmembrane glucose transport in human skeletal muscle (29) by combining the forearm perfusion technique (30-32) with the multiple tracer dilution technique (33). In the present study, we have applied the same strategy to assess the effect of insulin on transmembrane system A amino acid transport. Our findings show that physiologic hyperinsulinemia stimulates transmembrane inward amino acid transport by system $\mathrm{A}$ in human forearm muscle.

\section{Methods}

Subjects. Seven healthy young volunteers (four males and three females), ranging in age from 19 to $27 \mathrm{yr}$ and in ideal body weight (Metropolitan Life Insurance Tables, 1983) from 92 to $115 \%$ were studied. Subjects consumed a weight-maintaining diet that contained 200-250 $\mathrm{g}$ of carbohydrates for $3 \mathrm{~d}$ before study. No subject was taking any medication, and there was no family history of diabetes mellitus. All subjects had a normal oral glucose tolerance test (34). Each subject gave informed, written consent before participating in the study, which was approved by the Human Investigation Committees of the University of Texas Health Science Center at San Antonio and the Yale University School of Medicine (New Haven, CT).

Experimental design. At $0800 \mathrm{~h}$, after a 10-12 h overnight fast, subjects were admitted to the Clinical Research Center. Catheters were introduced percutaneously into the brachial artery and retrogradely into an ipsilateral deep forearm vein draining muscle. The tip of the deep forearm catheter was inserted for a distance of 2 in from the puncture site and could not be palpated in any of the subjects. Previous studies have documented that such catheter placement allows sampling of the muscle bed perfused by either the radial or ulnar artery (35). Catheter patency was maintained by a slow infusion of normal saline. To exclude blood flow from the hand, a pediatric sphygmomanometer cuff was inflated about the wrist to $100 \mathrm{~mm} \mathrm{Hg}$ above the systolic pressure for $2 \mathrm{~min}$ before and during each sampling interval, as well as for $2 \mathrm{~min}$ before and $10 \mathrm{~min}$ after the tracer injection. After a 60 -min basal period, insulin was infused directly into the brachial artery at 0.04 $\mathrm{mU} / \mathrm{min}$ per $\mathrm{kg}$ for $130 \mathrm{~min}$. Arterial and venous blood samples were collected at $-60,-30,-15$, and 0 min during the basal state and at 80 ,

1. Abbreviations used in this paper: MeAIB, 2-methylaminoisobutyric acid.
100 , and 130 min during the insulin infusion, when all measurements exhibited steady state conditions. Forearm blood flow was measured at each sampling interval from the dilution of indocyanine green dye infused intraarterially for $4 \mathrm{~min}(14-16)$. At -50 and $110 \mathrm{~min}$, a bolus of $\left[1-{ }^{3} \mathrm{H}\right]$-D-mannitol $(\sim 8 \mu \mathrm{Ci})$ plus $2-\left[1-{ }^{14} \mathrm{C}\right]$-methylaminoisobutyric acid (MeAIB) $(\sim 4 \mu \mathrm{Ci})$ (New England Nuclear, Boston, MA) was rapidly ( $3 \mathrm{~s}$ ) injected into the artery via the same syringe. Frequent blood samples (every 10-30 s) were drawn manually from the deep vein for $10 \mathrm{~min}$ thereafter. The midpoint of the collection time (6-8 s) was recorded for each blood sample, because owing to the inter- and intraindividual variability in the easiness of blood collection, no predetermined time schedule was used for the sampling of the washout curves. In the computerized analysis of the washout curves, each single point was considered to be the weighted average of tracer concentration within the time window corresponding to the collection time. Forearm volume was determined by water displacement. Forearm density was assumed to be 1 .

Analytical methods. Plasma insulin concentration was measured with a double antibody radioimmunoassay (4). The concentrations of indocyanine green dye in infusate and plasma were measured spectrophotometrically at $810 \mathrm{~nm}(14,15)$. Plasma amino acid (taurine, aspartate, threonine, serine, asparagine, glutamate + glutamine, glycine, alanine, valine, half cystine, methionine, isoleucine, leucine, tyrosine, and phenylalanine) concentrations were measured in sulfosalicylic acid extracts of plasma using an automated ion exchange chromatographic technique (D-500; Dionex Corp., Sunnyvale, CA ) (4). In five subjects, arterial and deep venous plasma potassium concentration was determined by flame spectrometry. Deep vein plasma samples collected after the tracer intraarterial injection were deproteinized according to Somogyi (36), dried, reconstituted, and mixed with scintillation fluid (Scintiverse; Fischer America, Inc., Waukesha, WI). Radioactivity was quantitated in a dual-channel liquid scintillation counter with external standard correction (Packard Instrument Co., Downers Grove, IL). Known volumes of all tracer infusates were added to plasma samples obtained from the same subject before the injection of the tracers, and plasma radioactivity was determined after Somogyi precipitation as described above.

Calculations. The net plasma exchange of substrates across the forearm (37) was calculated as:

net balance $=(A-V) \times P F$,

where $A$ and $V$ are the arterial and venous plasma concentrations, respectively, and $P F$ is forearm plasma flow.

Model-based measurement of transport. The principle underlying our experimental approach is that the reference nontransportable tracer, $\left[1-{ }^{3} \mathrm{H}\right]-\mathrm{D}-\mathrm{mannitol}$, traces the extracellular kinetic events (i.e., distribution with blood flow and diffusion through capillary walls into the interstitial fluids), whereas the test tracer, $2-\left[1-{ }^{14} \mathrm{C}\right]$-methylaminoisobutyric acid, also monitors the kinetics of membrane transport but not metabolism. The difference in the kinetics of the two tracers, therefore, is essentially caused by the transmembrane traffic of $2-\left[1-{ }^{14} \mathrm{C}\right]-$ methylaminoisobutyric acid through the system A amino acid transport.

To obtain detailed quantitative information from the dual tracer washout curves, we have developed a linear flow-compartmental model of the forearm system, which takes into account heterogeneities in properties, functions, and interactions between capillary-tissue units and measures amino acid transport into and out of the cell. A similar approach was recently proposed to measure glucose transport in the human forearm, to which the reader is referred for details on modeling rationale and methodology (29). Various candidate model structures were tested to describe not only the kinetics of amino acid transport into and out of the cell, but also blood flow in the vascular structure and diffusion into the interstitial fluid. Since neither mannitol nor MeAIB permeate red blood cells $(24,25)$, their extracellular kinetics are identical. The model, which was eventually chosen to analyze simultaneously the dual tracer washout curves is shown in Fig. 1. Compart- 


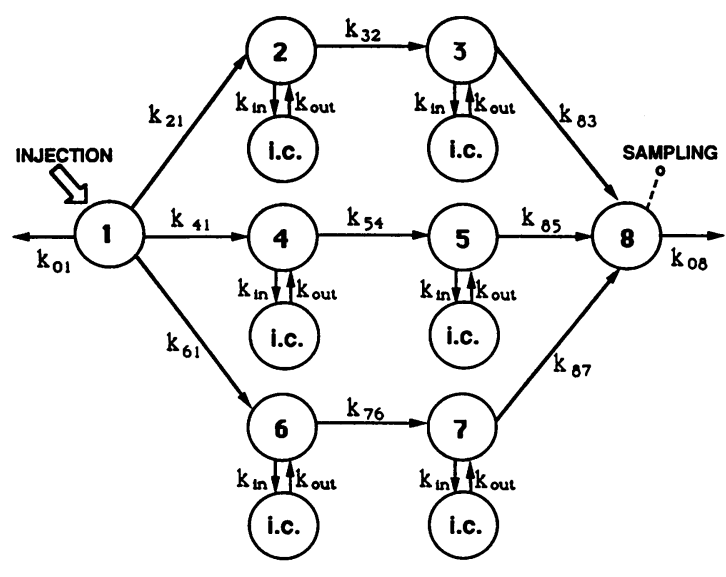

Figure 1. Multicompartmental model of D-mannitol and MeAIB kinetics in the human forearm. The two substances are injected in compartment $l$ (brachial artery), and their washout curves are measured in compartment 8 (deep vein). Between compartment $l$ and 8 , three parallel chains of compartments describe the capillary-tissue units. The i.c. compartments represent the intracellular space, which is accessible to MeAIB, but not to mannitol. Those k's that are labeled with numbers are the rate constants for the transfer of mannitol and MeAIB across the extracellular (blood vessels plus interstitial fluid) space. The two k's that are labeled as $k_{\text {in }}$ and $k_{\text {out }}$ are the rate constants of the bidirectional traffic of MeAIB into and out of the cellular space, which is mediated by system $A$ amino acid transport. The presence of $k_{01}$ in compartment 1 is needed because while the brachial artery is the only inlet, the sampling site (deep forearm vein) is only one of several forearm outlets and, therefore, only a variable fraction of the injected tracer dose is recovered in the sampling compartment. For further details, see text.

ments 1 and 8 are the plasma compartments where tracer input (injection) and measurement take place and, therefore, represent the arterial and venous portions of the model. The capillary-interstitial fluid section is represented by the three parallel chains of compartments; i.e., compartments 2 and $3 ; 4$ and 5; and 6 and 7 . The three chains are characterized by different rates to account for blood flow heterogeneity. The tissue portion is described by cellular compartments, briefly labeled as i.c., that are appended to and in exchange with the correspondent extracellular compartments in each chain. Two fractional irreversible losses, $k_{01}\left(\mathrm{~min}^{-1}\right)$ and $k_{08}\left(\mathrm{~min}^{-1}\right)$, are present in the model. The former accounts for the fact that only a fraction of the injected dose reaches the sampling compartment. The intrinsic symmetry of the model was resolved by imposing the following constraint on the model parameters:

$k_{83}>k_{85}>k_{87}\left(\min ^{-1}\right)$

This corresponds to label the three chains as fast (compartments 2 and 3 ), intermediary (compartments 4 and 5) and slow (compartments 6 and 7), respectively. An additional constraint was needed to ensure a priori unique identifiability of the extracellular portion of the model:

$k_{32}=k_{83} ; k_{54}=k_{85} ; k_{76}=k_{87}$

Finally, all the rate constants characterizing fractional MeAIB transport into the cell and those out of the cell in the three chains of compartments were assumed to be identical and named $k_{\text {in }}$ and $k_{\text {out }}$, respectively. It can be shown that $k_{\text {in }}$ and $k_{\text {out }}$ are a priori uniquely identifiable (29). The a priori uniquely identifiable parameterization of the model was fitted for each individual data set by using nonlinear least-squares parameter estimation. Measurement error was assumed additive, uncorrelated, of zero mean and with an experimentally determined variance. Coefficients of variation ranged from 1 to $6-8 \%$ and were higher with lower counts. The conversational version (CONSAM) of the SAAM program was used in model parameter estimation $(38,39)$. In all cases, model fit was very good and the transport rate parameters were estimated with good precision. The median coefficients of variation of $k_{\text {in }}$ were 5\% (range: 3-11\%) in the basal state and 6\% (range: 4-10\%) during hyperinsulinemia, respectively. The median coefficients of variation of $k_{\text {out }}$ were $11 \%$ (range: $5-26 \%$ ) in the basal state and $19 \%$ (range: $4-46 \%$ ) during hyperinsulinemia, respectively.

The transfer of MeAIB into and out of the cell takes place in the presence of several other amino acids which are substrates for the same transport process. These amino acids act as competitive inhibitors of MeAIB transport. It is of interest to explore the mathematical relationship between the fractional rates of MeAIB transport ( $k_{\text {in }}$ and $\left.k_{\text {out }}\right)$ and the kinetic parameters of system A transport. Let's focus on $k_{\text {in }}$ and assume that system $A$ obeys Michaelis-Menten kinetics. It can be shown (40) that the influx of MeAIB is given by the following equation:

Influx $_{\text {MeAIB }}=\left(V_{\max }^{\prime} * K_{\mathrm{m}} / K_{\mathrm{m}}^{\prime}\right) * S^{\prime} /\left(K_{\mathrm{m}}+S\right)$

where $V_{\max }^{\prime}$ is the maximal influx of MeAIB, $K_{\mathrm{m}}$ is the Michaelis-Menten constant for the transport of a competing amino acid, $K_{\mathrm{m}}^{\prime}$ is the Michaelis-Menten constant for MeAIB transport, $S^{\prime}$ is the $\left[{ }^{14} \mathrm{C}\right] \mathrm{MeAIB}$ concentration in the extracellular fluids, and $S$ is the concentration of a competing amino acid.

As a result of our tracer study, transmembrane inward flux of tracer MeAIB is given also by the following equation:

Influx $_{\text {MeAIB }}=k_{\text {in }} * S^{\prime} * V_{\mathrm{D}}$

where $k_{\text {in }}$ is the rate constant determined in the present study, and $V_{\mathrm{D}}$ is the extracellular volume of distribution of MeAIB. Note that since MeAIB is present in tracer amounts, the rate of influx is a linear function of MeAIB concentration.

By equating equations ( 3 ) and (4), one obtains:

$k_{\text {in }}=\left(1 / V_{\mathrm{D}}\right) *\left(V_{\text {max }}^{\prime} / K_{\mathrm{m}}^{\prime}\right) *\left\{K_{\mathrm{m}} /\left(K_{\mathrm{m}}+S\right)\right\}$

Equation (5) can also be rewritten in the following form:

$k_{\text {in }}=\left(1 / V_{\mathrm{D}}\right) *\left(V_{\text {max }}^{\prime}\right) *\left\{1 /\left[K_{\mathrm{m}}^{\prime}+S *\left(K_{\mathrm{m}}^{\prime} / K_{\mathrm{m}}\right)\right]\right\}$

Thus, assuming that the extracellular volume of distribution of MeAIB is invariant and that any change in the kinetic parameters of MeAIB transport is accompanied by parallel changes in the kinetic parameters of the amino acids sharing the same transport system, $k_{\text {in }}$ can increase as a consequence of an increase in transport $V_{\max }^{\prime}$ (increased transport capacity), or a decrease in transport $K_{m}^{\prime}$ (increased transport affinity), or a decrease in $S$, that is the concentration of the amino acid(s) traveling through the same carriers. By a similar line of reasoning, an analogous equation can be derived for $k_{\text {out }}$. Therefore, under the same set of assumptions, $k_{\text {out }}$ can increase as a consequence of either an increase in $V_{\max }^{\prime}$ or a decrease in $K_{m}^{\prime}$ of outward transport, or a decrease in the intracellular concentration of those amino acids traveling through the same carrier.

Statistical analysis. All data are presented as mean \pm SEM. All results were compared by Student's $t$ test for paired data (41). The results of forearm blood flow and substrate exchanges during the basal and insulin infusion periods represent the mean of three steady state determinations in each subject for each period.

\section{Results}

Basal forearm muscle amino acid and potassium exchange. After the overnight fast, plasma insulin and glucose concentrations were $6.4 \pm 1.6 \mu \mathrm{U} / \mathrm{ml}$ and $90 \pm 2.6 \mathrm{mg} / \mathrm{dl}$, respectively. A significant uptake of glucose $(1.04 \pm 0.27 \mathrm{mg} / \mathrm{min}$ per $\mathrm{kg})$ was demonstrable. Deep venous total plasma amino acid concentration was higher than arterial $(1,844 \pm 95$ vs $1,754 \pm 86 \mu \mathrm{M}, P$ $<0.01$ ). A net output of amino acids from forearm muscle 
was, therefore, documented $(-2,630 \pm 1,100 \mathrm{nmol} / \mathrm{min}$ per $\mathrm{kg})$. Also, deep venous plasma potassium concentration was higher than arterial $(4.42 \pm 0.1$ vs $4.23 \pm 0.1 \mathrm{mM}, P<0.05)$, accounting for a net potassium output from forearm muscle $(-3,800 \pm 970 \mathrm{nmol} / \mathrm{min}$ per $\mathrm{kg})$. Forearm blood flow in the basal state averaged $44.3 \pm 11 \mathrm{ml} / \mathrm{min}$ per $\mathrm{kg}$.

Basal system $A$ amino acid transport activity. The washout curves of $\left[1-{ }^{3} \mathrm{H}\right]-\mathrm{D}-$ mannitol and $2-\left[1-{ }^{14} \mathrm{C}\right]$-methylaminoisobutyric acid in deep venous plasma displayed a parallel behavior. Both showed a peak within the first $30 \mathrm{~s}$, followed by a quick fall, and then a slower washout phase. At all time points, in all subjects, the dose-normalized concentration of 2-[1$\left.{ }^{14} \mathrm{C}\right]$-methylaminoisobutyric acid was lower than the $\left[1-{ }^{3} \mathrm{H}\right]-$ D-mannitol concentration (see Fig. 2 for a typical experiment). These results document that MeAIB had gained access to a space inaccessible to mannitol. As MeAIB is specific for system A amino acid transport $(24,25)$, this primary data was taken as evidence for the presence of an active system A (or system A-like) transport in human deep forearm tissues (skeletal muscle).

The washout curves of mannitol and MeAIB were then analyzed using the multicompartmental model described above. The basal fractional rate of inward transmembrane MeAIB transport was $11.8 \cdot 10^{-2} \pm 1.7 \cdot 10^{-2} \cdot \min ^{-1}$ and this was approximately fourfold greater than the rate constant of outward transport, $3.4 \cdot 10^{-2} \pm 0.51 \cdot 10^{-2} \cdot \mathrm{min}^{-1}$.

Response to local hyperinsulinemia. Infusion of insulin into the brachial artery raised the deep venous insulin concentration to $76 \pm 8 \mu \mathrm{U} / \mathrm{ml}(P<0.01)$, for $130 \mathrm{~min}$. Insulin concentration in the contralateral arm vein showed no detectable change during the study $(7 \pm 2 \mu \mathrm{U} / \mathrm{ml})$. Arterial plasma amino acid and potassium concentrations did not change during the insulin infusion $(1,730 \pm 106 \mu \mathrm{M}$ and $4.10 \pm 0.08 \mathrm{mM}$, respectively, $P=$ NS vs baseline for both). Forearm blood flow also was unchanged during the intraarterial infusion $(46.4 \pm 9.2$ vs $44.3 \pm 11 \mathrm{ml} / \mathrm{min}$ per $\mathrm{kg}$ in the postabsorptive state, $P=\mathrm{NS}$ ).

Both amino acid and potassium concentrations in deep venous plasma decreased from the basal values $(1,677 \pm 90 \mu \mathrm{M}$ and $4.03 \pm 0.08 \mathrm{mM}, P<0.01$ and $P<0.05$ vs baseline values, respectively). Therefore, during the insulin infusion, there was a positive amino acid balance across forearm muscle $(1,610 \pm 600 \mathrm{nmol} / \mathrm{min}$ per $\mathrm{kg})$, while the potassium balance

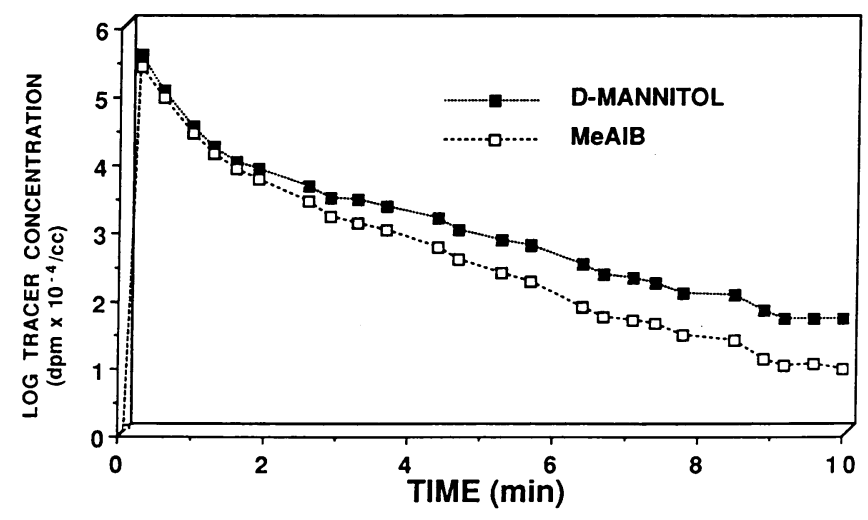

Figure 2. A typical dual tracer washout curve. The concentrations $\left(\mathrm{dpm} \times 10^{-4} / \mathrm{cc}\right)$ have been normalized to the respective injected doses to allow the direct comparison of the two concentrations and have been transformed into base $e$ logarithms.
Table I. Arterial and Venous Concentrations of System A Amino Acids

\begin{tabular}{lccccc}
\hline & \multicolumn{3}{c}{ Basal } & & \multicolumn{2}{c}{ Insulin } \\
\cline { 2 - 3 } \cline { 5 - 6 } & Artery & Vein & & Artery & Vein \\
\hline & $\mu M$ & $\mu M$ & & $\mu M$ & $\mu M$ \\
Amino acids & & & & \\
Glycine & $196 \pm 16$ & $214 \pm 19$ & & $196 \pm 15$ & $194 \pm 15$ \\
Alanine & $201 \pm 14$ & $261 \pm 18$ & & $182 \pm 15$ & $227 \pm 21$ \\
Threonine & $146 \pm 15$ & $163 \pm 17$ & & $140 \pm 13$ & $141 \pm 13$ \\
Asparagine & $47 \pm 3$ & $56 \pm 4$ & & $47 \pm 3$ & $46 \pm 2$ \\
Serine & $114 \pm 6$ & $107 \pm 7$ & & $119 \pm 6$ & $93 \pm 5$ \\
Methionine & $20 \pm 1$ & $23 \pm 2$ & & $18 \pm 1$ & $19 \pm 1$ \\
& & & & \\
\hline
\end{tabular}

Arterial and forearm deep venous concentrations in the basal state and during local hyperinsulinemia of six amino acids, which are typical substrates for system $\mathrm{A}$ amino acid transport. The data are presented as mean \pm SEM.

was not significantly different from zero $(2,260 \pm 1,330 \mathrm{nmol} /$ min per kg). Both exchanges, however, were significantly altered when compared to the postabsorptive values $(P<0.01$ for both vs baseline).

Net phenylalanine and tyrosine exchanges, which, at steady state, monitor the balance between bulk protein synthesis and breakdown in forearm muscle $(42,43)$, shifted from a net output in the postabsorptive state to a zero balance $(-146 \pm 47$ vs $16.3 \pm 51 \mathrm{nmol} / \mathrm{min}$ per $\mathrm{kg}$ for phenylalanine and $-173 \pm 34 \mathrm{vs}$ $15.5 \pm 14.3 \mathrm{nmol} / \mathrm{min}$ per $\mathrm{kg}$ for tyrosine, $P<0.01 \mathrm{vs}$ baseline for both), showing that bulk protein synthesis and breakdown were in equilibrium during hyperinsulinemia.

The concentrations of the system A substrates measured in the present study (glycine, alanine, threonine, asparagine, serine, and methionine) are presented in Table I. Arterial concentrations remained unchanged throughout the study, whereas venous concentrations fell significantly during;ocal hyperinsulinemia. The individual data for net balances of glycine, alanine, threonine, asparagine, serine, and methionine are shown in Table II. During insulin infusion, the net balances of glycine, alanine, threonine, asparagine, and methionine were significantly decreased $(P<0.05-0.01$ vs baseline $)$, whereas serine showed a net positive balance $(P<0.02$ vs baseline $)$. Thus, all the naturally occurring system A substrates displayed a qualitatively similar response to insulin. The individual data of MeAIB transport also are displayed in Table II. Intraarterial insulin infusion increased the fractional transmembrane inward transport $\left(k_{\text {in }}\right)$ of MeAIB by $16 \pm 4.5 \%$ from $11.8 \cdot 10^{-2} \pm 1.7 \cdot 10^{-2} \cdot \mathrm{min}^{-1}$ to $13.8 \cdot 10^{-2} \pm 2.2 \cdot 10^{-2} \cdot \mathrm{min}^{-1}$ ( $P<0.02$ vs the postabsorptive value), while the fractional outward transmembrane transport $\left(k_{\text {out }}\right)$ decreased slightly ( from $3.4 \cdot 10^{-2} \pm 0.51 \cdot 10^{-2}$ to $2.9 \cdot 10^{-2} \pm 0.23 \cdot 10^{-2} \cdot \mathrm{min}^{-1}$, $P=$ NS).

\section{Discussion}

Suitable in vivo techniques are currently available to monitor muscle protein turnover in man $(43,44)$ and have demonstrated that the primary effect of physiologic hyperinsulinemia on amino acid metabolism is exerted by inhibiting the rate of 
Table II. Net Balances of System A Amino Acids and Fractional System A Transport Activity in Human Forearm Tissues

\begin{tabular}{|c|c|c|c|c|c|c|c|c|c|c|c|c|c|c|c|c|}
\hline & \multicolumn{2}{|c|}{ Gly } & \multicolumn{2}{|c|}{ Ala } & \multicolumn{2}{|c|}{ Thr } & \multicolumn{2}{|c|}{ Asn } & \multicolumn{2}{|c|}{ Ser } & \multicolumn{2}{|c|}{ Met } & \multicolumn{2}{|c|}{$\mathbf{K}_{\text {in }}$} & \multicolumn{2}{|c|}{$\mathrm{K}_{\text {out }}$} \\
\hline & B & I & B & I & B & I & B & I & B & I & B & I & B & I & B & I \\
\hline \multicolumn{17}{|l|}{ Subjects } \\
\hline B.C. & -399 & +175 & -1090 & -710 & -345 & +172 & -86 & +37 & +340 & +661 & -95 & +32 & 9.8 & 13.0 & 1.9 & 2.0 \\
\hline T.J. & -370 & +82 & -1360 & -1560 & -495 & +235 & -222 & +57 & +337 & +1013 & -109 & +3 & 12.0 & 12.4 & 3.0 & 3.0 \\
\hline C.B. & -48 & -66 & -990 & -586 & -140 & +37 & -79 & +43 & -99 & +397 & -28 & +34 & 16.0 & 19.0 & 3.3 & 3.1 \\
\hline E.M. & -542 & -26 & -706 & -665 & -617 & -47 & -315 & +95 & -14 & +393 & -16 & +14 & 12.0 & 14.4 & 2.5 & 2.5 \\
\hline A.L. & -1866 & -775 & -3760 & -2220 & -1150 & -570 & -752 & +89 & -461 & +802 & -255 & +29 & 19.0 & 23.0 & 4.5 & 4.0 \\
\hline S.D. & -498 & -48 & -2380 & -1700 & -410 & -129 & -252 & -36 & +437 & +448 & -91 & -27 & 6.2 & 6.2 & 5.8 & 3.0 \\
\hline R.W. & -138 & +198 & -735 & -581 & -107 & -16 & -76 & -34 & +444 & +597 & -49 & -45 & 7.3 & 8.7 & 2.6 & 3.0 \\
\hline Mean & -552 & -66 & -1574 & -1146 & -467 & -56 & -255 & +36 & +140 & +616 & -92 & +5.6 & 11.8 & 13.8 & 3.4 & 2.9 \\
\hline SEM & 230 & 125 & 420 & 260 & 133 & 99 & 90 & 20 & 129 & 87 & 30 & 12 & 1.7 & 2.2 & 0.5 & 0.2 \\
\hline I vs B & \multicolumn{2}{|c|}{$P<0.01$} & \multicolumn{2}{|c|}{$P<0.05$} & \multicolumn{2}{|c|}{$P<0.01$} & \multicolumn{2}{|c|}{$P<0.05$} & \multicolumn{2}{|c|}{$P<0.02$} & \multicolumn{2}{|c|}{$P<0.05$} & \multicolumn{2}{|c|}{$P<0.02$} & \multicolumn{2}{|c|}{$P=\mathrm{NS}$} \\
\hline
\end{tabular}

Individual results for forearm net balances of glycine (Gly), alanine (Ala), threonine (Thr), asparagine (Asp), serine (Ser), methionine (Met), and for fractional inward $\left(k_{\text {in }}\right)$ and outward $\left(k_{\text {out }}\right)$ transport of 2-methylaminoisobutyric acid (MeAIB) in the basal state (B) and during local hyperinsulinemia (I). These amino acids are all typical substrates for system $\mathrm{A}$ amino acid transport. The units of forearm balances are nmol/ $\mathrm{min} / \mathrm{kg}$ of forearm tissues. The - sign denotes release, whereas the + sign denotes uptake. The units of fractional MeAIB transport are min ${ }^{-1} \cdot 10^{-2}$.

protein breakdown $(1-6,8-15)$. However, the classic tracer techniques, while allowing the investigator to divide the net amino acid exchange across the limb into a protein synthetic and a protein degradative rate (43), are unable to discern more proximal sites of action, which could be involved in the overall response of human muscle to insulin.

The present study shows that with an appropriate experimental strategy, it is possible to gain selective information about the activity of system $A$ amino acid transport in human deep forearm tissues. As the deep forearm tissues are almost entirely composed of skeletal muscle and, in the aggregate, all the other cellular types (e.g., endothelial cells and fibroblasts) represent a minute amount $(<2 \%)$ of the total cellular mass, the metabolic events observed in the present study primarily reflect skeletal muscle metabolism.

The multiple tracer technique used in this study was developed in analogy with the tracer technique earlier established for the assessment of glucose transport in forearm muscle (29). Forearm blood flow is only $\sim 1 \%$ of the cardiac output. Consequently, the amount of tracer recirculation is negligible and local injection of the tracers into the brachial artery allows us to interpret the time course of the concentration in the deep vein as the result of first-pass events.

The multiple tracer dilution technique can be viewed as a system of built-in controls (33). Since mannitol does not enter the cell and MeAIB only is transported, but not metabolized $(24,25)$, and since this pair of substances has comparable molecular weights, any kinetic difference between the two molecules must reflect cellular transport activity. By choosing MeAIB, according to the current operational classification of the amino acid transport systems, we selected a specific amino acid carrier (system A) for our investigation. As a result, the results that we have obtained apply only to those amino acids, whose traffic across the plasma membrane is entirely, or to a substantial extent, mediated by the system A carrier $(24,25)$.

The kinetic analysis used in this study mandates that the requirements of stationarity for the tracee be fulfilled $(29,33)$. On practical grounds, we achieved these conditions by per- forming our injections in two different steady states, as documented by constant arterial-venous substrate concentrations and constant blood flow. Moreover, because the amino acid carriers are inherently nonlinear, the amino acid concentration at the inlet must be unchanged to draw comparisons between the two steady states. This requirement also was fulfilled in the present study, as described in the results.

The present study shows that system A (or system A-like) transport activity is present in human forearm muscle and this represents the first in vivo evidence to demonstrate the presence of this insulin-stimulatable amino acid transport system in man. These results are in agreement with a previous report documenting the existence of system $\mathrm{A}$ transport in rat soleus muscle studied in vitro $(45,46)$.

An interesting feature of system A transport, as assessed by our approach, is that the rates of fractional inward and outward transport differed considerably, the former being three- to fourfold greater than the latter. This finding is consistent with the well-known asymmetry of system $\mathrm{A}$, which has been described by in vitro studies $(24,25)$. However, it may also be caused by a higher amino acid concentration on the inner side of the plasma membrane (7), because the system A carrier is nonlinear (25), and an increased substrate concentration would decrease the fraction of the cellular pool (rate constant), which is transported outside of the cell.

Among the amino acids whose transport is regulated by the activity of the system A carrier (Tables I and II), alanine and methionine are prominent in influencing the overall amino acid metabolism of forearm muscle. It should be noted, however, that both alanine and methionine also may be carried to a substantial degree by system ASC and system $\mathrm{L}$, respectively $(24,25)$. Alanine plays a key role in transferring $\mathrm{NH}_{3}$ groups, produced by transamination and deamination of other amino acids, to the splanchnic tissues and in furnishing carbon atoms for hepatic gluconeogenesis (47). Methionine has a high intracellular turnover, because it is involved in the initiation of peptide synthesis and in a variety of transmethylation and transsulfuration reactions $(48,49)$. It is likely, therefore, that the activ- 
ity of system A transport can influence some, or all, of these relevant steps of amino acid metabolism.

For both phenylalanine/tyrosine and potassium, the exposure of the forearm tissues to hyperinsulinemia shifted the balance from a net significant output (documenting that release was exceeded uptake) in the postabsorptive state to a zero net balance indicating equivalence of uptake and release $(42,43)$. These results confirm previous studies $(14,15,30-32)$, and may be interpreted to reflect insulin-mediated inhibition of protein breakdown $(14,15)$ and stimulation of $\mathrm{Na}, \mathrm{K}-\mathrm{ATPase}$ (50), respectively.

The most relevant result of this study is that insulin increases the fractional inward transmembrane transport of amino acids that are carried by system $\mathrm{A}$, while the fractional outward transport is not stimulated, or perhaps somewhat decreased. This observation shows that at least one of the sites where insulin exerts its action on forearm muscle protein metabolism involves amino acid transport across the plasma membrane. A germane question is whether this change in amino acid transport observed during hyperinsulinemia may be attributed to insulin per se, or to the insulin-induced fall in the amino acid concentration bathing the cell, which, in our study, is reflected by the decrease in venous amino acid concentration. The impact that the decrease in amino acid concentration observed during hyperinsulinemia in the present study may have on $k_{\text {in }}$ can be best appreciated assuming that no change occurs in $V_{\max }^{\prime}, K_{\mathrm{m}}^{\prime}$, and $K_{\mathrm{m}}$, and rewriting equation 5 (see Methods) for both the basal state (indexed as 1) and the insulinized state (indexed as 2):

$k_{\text {in(1) }}=\left(1 / V_{\mathrm{D}}\right) *\left(V_{\max }^{\prime} / K_{\mathrm{m}}^{\prime}\right) *\left[K_{\mathrm{m}} /\left(K_{\mathrm{m}}+S_{(1)}\right)\right]$

$k_{\text {in(2) }}=\left(1 / V_{\mathrm{D}}\right) *\left(V_{\max }^{\prime} / K_{\mathrm{m}}^{\prime}\right) *\left[K_{\mathrm{m}} /\left(K_{\mathrm{m}}+S_{(2)}\right)\right]$

By simple recombination of (6) and (7), it follows that:

$k_{\mathrm{in}(2)} / k_{\mathrm{in}(1)}=\left[K_{\mathrm{m}}+S_{(1)}\right] /\left[K_{\mathrm{m}}+S_{(2)}\right]$

The $K_{\mathrm{m}}$ 's of system A amino acid substrates (except alanine) are at least one order of magnitude higher than their circulating concentrations and range between $0.9 \mathrm{mM}$ for alanine and $\sim 4$ $\mathrm{mM}$ for glycine (51). By substituting the respective $K_{\mathrm{m}}$ 's and venous concentrations ( see Table I) in the second member of equation, it can be calculated that the decrease in alanine concentration can justify no more than a $3.3 \%$ increase in system $A$ fractional inward transport, whereas the decrease in glycine would account for only a $0.5 \%$ increase. Thus, we think that the increase in system A fractional inward transport documented in this study $(\sim 16 \%)$ can be attributed primarily to a direct effect of insulin on system A transport.

Several mechanisms may be involved in the effect of insulin on system A amino acid transport. During hyperinsulinemia, there was a change in potassium balance, reflecting in all likelihood an increase in $\mathrm{Na}, \mathrm{K}-\mathrm{ATPase}$ activity $(30,32,50)$ and hyperpolarization of plasma membrane (52) accompanied by a steeper electrochemical sodium gradient across the cell membrane. Because amino acid transport by system $A$ is coupled to $\mathrm{Na}^{+}$transport $(24,25)$, hyperpolarization of the cell membrane and enhanced $\mathrm{Na}^{+}$influx would be expected to augment the inward transport of system $A$ transported amino acids (53). Conversely, a decrease in intracellular sodium activity might be expected to decrease the outward flux of amino acids. Another possibility is that insulin may play a direct role by enhancing the $K_{\mathrm{m}}$ of the inward system while decreasing the $K_{\mathrm{m}}$ of outward transport, as shown in in vitro systems.

Another potential mechanism involves the antiproteolytic effect of the hormone. As elegantly shown by Gelfand and Barrett under similar experimental conditions (14), insulin decreases protein breakdown, but does not increase steady state net amino acid uptake from the plasma pool. The result of inhibiting this cell-borne input of amino acid into the cellular amino acid pool should be a fall of the intracellular amino acid concentration. In fact, we previously have demonstrated a generalized decline in intracellular amino acid concentrations in muscle after systemic insulin infusion (7). Since system A transport is characterized by transinhibition $(24,25)$, a decrease of intracellular amino acid concentration would relieve the inhibition of inward transport and increase its efficiency, while simultaneously leading to an increase in the fractional outward transport of system A substrates. The latter phenomenon, which was not observed in our study, could have been offset by membrane hyperpolarization and/or decreased intracellular $\mathrm{Na}^{+}$activity induced by hyperinsulinemia. However, to our knowledge, no data are available about the behavior of intracellular muscle amino acid concentrations during combined hyperinsulinemia/euaminoacidemia, and the last potential mechanism should, therefore, be regarded as speculative.

The percent increase in inward MeAIB transport activity measured in the present study was $\sim 16 \%$, but it is entirely consistent with the observation that all kinetic changes of forearm amino acid metabolism were brought about by decrements in the deep venous amino acid concentration of only $\sim 9-10 \%$. Nevertheless, it could be argued that this change in amino acid transport activity is small in comparison with the changes in the rates of amino acid exchange across the forearm tissues (Table II). The crux of this issue is that net amino acid transport is the result of two unidirectional transmembrane fluxes. Thus, relatively little changes in either or both unidirectional fluxes are stoichiometrically compatible with major changes in the net transport of amino acids. Our results document that in the basal state, in spite of net amino acid release, the activity of the inward system $A$ amino acid transport and, therefore, the inward movement of system A substrates across the plasma membrane is quite significant. Previous studies also have shown that, in the basal state, the forearm takes up significant amounts of labeled amino acids (e.g., phenylalanine and leucine), even though the net balance of unlabeled substance is negative $(14,16,54)$. Both lines of experimental evidence point out that the postabsorptive negative balance of amino acids in the human forearm is composed by two opposite transmembrane fluxes, whose order of magnitude is several-fold larger that the net transmembrane substrate movement. It should also be noted that not only typical system A substrates, but also phenylalanine and tyrosine shifted from a net output to a zero balance during local insulinization of forearm tissues. The latter amino acids are substrates for the $\mathrm{L}$ system, which reportedly is insulin insensitive $(24,25)$. Thus, the variations in the activity of transmembrane amino acid transport reported in the present study are hardly a primary causal factor of the insulin-induced changes in forearm amino acid balance, but are likely to play only an ancillary role. Yet, the potential physiologic consequences of this change in transmembrane amino acid transport deserve to be carefully appraised.

By augmenting system A transport activity, insulin would 
increase the transmembrane unidirectional inward flux of methionine and alanine, as long as no counterbalancing changes in the ASC and L systems occurred. This is likely to be the case because both methionine and alanine showed, indeed, a significant change in their net balance across the forearm tissues ( Table II). Hence, more methionine would be available from the circulating pool to sustain the rates of transsulfuration, transmethylation, and methionine-tRNA formation in forearm muscle. The latter phenomenon may be of paramount importance, because the rate of methionine-tRNA synthesis must supply, not only the cells' requirements for methionine as a building block for peptides, but also for the initiation of peptide chains formation since methionine-tRNA is the first activated amino acid (21). When viewed in this context, methionine is invested with a metabolic role which goes beyond that of simply being an essential amino acid, and, under some circumstances, its availability may become rate limiting for protein synthesis. Our results also have important relevance to the metabolism of alanine, a key gluconeogenic substrate (47). The increased inward flux of alanine through system $A$ in response to insulin would occur simultaneously with the inhibition of proteolysis $(14,15)$, and thus limit the supply of muscle alanine for hepatic gluconeogenesis.

Our findings also have relevance to the more global effect of insulin in the regulation of proteolysis and protein synthesis in forearm muscle. Inhibition of protein breakdown by insulin consistently has been shown in a number of previous studies (1-6, 8-16), but stimulation of bulk protein synthesis during hyperinsulinemia was observed only when concomitant hyperaminoacidemia occurred $(3,4,55)$. This finding, in conjunction with the observation that combined hyperinsulinemia/ hypoaminoacidemia is associated with a decrease of protein synthetic rate $(1-4,16)$, makes a strong case for an intracellular substrate effect of amino acids to stimulate bulk protein synthesis. However, if one holds that hyperinsulinemia per se does not directly stimulate bulk protein synthesis in vivo, it is not clear why protein synthesis does not fall under experimental conditions of hyperinsulinemia/euaminoacidemia when the insulin-induced inhibition of protein breakdown limits the intracellular source of amino acids for bulk protein synthesis $(4,14,15)$. This paradox can be resolved if either the transmembrane amino acid inward transport or the efficiency (lower $K_{\mathrm{m}}$ and / or higher $V_{\max }$ ) of the rate determining step(s) of protein synthesis are increased by hyperinsulinemia. Our data show that the former mechanism holds for at least one amino acid transport system and demonstrate that coordinated effects and multiple sites are involved in the regulation by insulin of amino acid/protein metabolism in human skeletal muscle.

\section{Acknowledgments}

The authors wish to thank Kathy Starick Zych, Rita Mirabelli, Debra Mitchell, and Barbara Washington for the highly competent nursing care of the volunteers. Ralph Jacob, Syed Hasan, Cristopher Carroll, Howard Christophersson, Anna Crowder, and Ronald Klein provided superb technical assistance.

This work was supported in part by National Institutes of Health grants DK24092, a Veterans Administration Merit Award, General Clinical Research Center grant M01-RR-01346, funds from the Veterans Administration Medical Research Service and Geriatric Research Education and Clinical Center, and by a grant from the Italian
Ministero dell'Universitá e della Ricerca Scientifica e Tecnologica (40\%).

R. C. Bonadonna was the recipient of a fellowship from Juvenile Diabetes Foundation International (388041). M. P. Saccomani was partly supported by the Resource Facility for Kinetic Analysis, University of Washington (Seattle, WA).

\section{References}

1. Fukagawa, N. K., K. L. Minaker, J. W. Rowe, M. N. Goodman, D. E. Matthews, D. M. Bier, and V. R. Young. 1985. Insulin-mediated reduction of whole-body protein breakdown. Dose-response effects on leucine metabolism in postabsorptive men. J. Clin. Invest. 76:2306-2311.

2. Tessari, P., R. Trevisan, S. Inchiostro, S. Vigili de Kreutzenberg, G. Biolo, E. Duner, A. Tiengo, and G. Crepaldi. 1986. Dose-response curves of the effects of insulin on leucine kinetics in man. Am. J. Physiol. 251:E334-E343.

3. Tessari, P., S. Inchiostro, G. Biolo, R. Trevisan, G. Fantin, M. C. Marescotti, E. Iori, A. Tiengo, and G. Crepaldi. 1987. Differential effects of hyperinsulinemia on leucine-carbon metabolism in vivo. Evidence for distinct mechanisms in regulation of net amino acid deposition. J. Clin. Invest. 79:1062-1069.

4. Castellino, P., L. Luzi, D. C. Simonson, M. Haymond, and R. A. DeFronzo. 1987. Effect of insulin and plasma amino acid concentration on leucine metabolism in man: role of substrate availability on estimates of whole body protein synthesis. J. Clin. Invest. 80:1784-1793.

5. Shangraw, R. E., C. A. Stuart, M. J. Prince, E. J. Peters, and R. R. Wolfe. 1988. Insulin responsiveness of protein metabolism in vivo following bedrest in humans. Am. J. Physiol. 255:E548-E558.

6. Flakoll, P. J., M. Kulaylat, M. Frexes-Steed, H. Hourani, L. L. Brown, J. O. Hill, and N. N. Abumrad. 1989. Amino acids augment insulin's suppression of whole body proteolysis. Am. J. Physiol. 257:E839-E847.

7. Del Prato, S., R. A. DeFronzo, P. Castellino, J. Wahren, and A. Alverstrand. 1990. Regulation of amino acid metabolism by epinephrine. Am. J. Physiol. 258:E878-E887.

8. Frexes-Steed, M., M. L. Warner, N. Bulus, P. Flakoll, and N. N. Abumrad. 1990. Role of insulin and branched-chain amino acids in regulating protein metabolism during fasting. Am. J. Physiol. 258:E907-E917.

9. Robert, J. J., B. Beaufrere, J. Kosiet, J. F. Desieux, D. M. Bier, V. R. Young, and $H$. Lestradet. 1985. Whole-body de novo amino acid synthesis in type 1 (insulin-dependent) diabetes studied with stable-isotope labelled leucine, alanine and glycine. Diabetes. 34:67-73.

10. Umpleby, A. M., M. A. Boroudjerdi, P. M. Brown, E. R. Carson, and P. E. Sonksen. 1986. The effect of metabolic control on leucine metabolism in type 1 (insulin-dependent) diabetic patients. Diabetologia. 29:131-141.

11. Pacy, P. J., K. S. Nair, C. Ford, and D. Halliday. 1989. Failure of insulin infusion to stimulate fractional muscle protein synthesis in type 1 diabetic patients. Anabolic effect of insulin and decreased proteolysis. Diabetes. 38:618-624.

12. Bennett, W. M., A. A. Connacher, K. Smith, R. T. Jung, and M. J. Rennie. 1990. Inability to stimulate skeletal muscle or whole body protein synthesis in type 1 (insulin-dependent) diabetic patients by insulin-plus-glucose during amino acid infusion: studies of incorporation and turnover of tracer $L-\left[1-{ }^{13} \mathrm{C}\right]$ leucine. Diabetologia. 33:43-51.

13. Lundholm, K., L. Edstrom, L. Ekman, I. Karlberg, P. Walker, and T. Schersten. 1981. Protein degradation in human skeletal muscle: the effect of insulin, leucine, amino acids and ions. Cli. Sci. (Lond.). 60:319-326.

14. Gelfand, R. A., and E. J. Barrett. 1987. Effect of physiologic hyperinsulinemia on skeletal muscle protein synthesis and breakdown in man. J. Clin. Invest. 80:1-7.

15. Fryburg, D. A., R. A. Gelfand, and E. J. Barrett. 1991. Growth hormone acutely stimulates forearm muscle protein synthesis in normal humans. Am. J. Physiol. 260:E499-E504.

16. Tessari, P., S. Inchiostro, G. Biolo, E. Vincenti, and L. Sabadin. 1991. Effects of acute systemic hyperinsulinemia on forearm muscle proteolysis in healthy man. J. Clin. Invest. 88:27-33.

17. Manchester, K. L., and F. G. Young. 1958. The effect of insulin on the incorporation of amino acid into protein of normal rat diaphragm in vitro. Bio chem. J. 70:353-358.

18. Jefferson, L. S., J. O. Koehler, and H. E. Morgan. 1972. Effect of insulin on protein synthesis in skeletal muscle of an isolated perfused preparation of rat hemicorpus. Proc. Natl. Acad. Sci. USA. 69:816-820.

19. Jefferson, L. S., J. B. Li, and S. R. Rannels. 1977. Regulation by insulin of amino acid release and protein turnover in the perfused rat hemicorpus. J. Biol. Chem. 252:1476-1483.

20. Garlick, P. J., M. Fern, and V. R. Preedy. 1983. The effect of insulin infusion and food intake on muscle protein synthesis in postabsorptive rats. Biochem. J. 210:669-676.

21. Kimball, S. R., and L. S. Jefferson. 1988. Cellular mechanisms involved in the action of insulin on protein synthesis. Diabetes Metab. Rev. 4:773-787.

22. Airhart, J., J. A. Arnold, W. S. Stirewalt, and R. B. Low. 1982. Insulin 
stimulation of protein synthesis in cultured skeletal and cardiac muscle cells. $A m$. J. Physiol. 243:C81-C86.

23. De Feo, P., M. Gan Gaisano, and M. W. Haymond. 1991. Differential effects of insulin deficiency on albumin and fibrinogen synthesis in humans. $J$. Clin. Invest. 88:833-840.

24. Shotwell, M. A., M. S. Kilberg, and D. L. Oxender. 1983. The regulation of neutral amino acid transport in mammalian cells. Biochim. Biophys. Acta. 737:267-284.

25. Christensen, H. N. 1990. Role of amino acid transport and countertransport in nutrition and metabolism. Physiol. Rev. 70:43-77.

26. Marshall, S., and R. Monzon. 1989. Amino acid regulation of insulin action in isolated adipocytes. Selective ability of amino acids to enhance both insulin sensitivity and maximal insulin responsiveness of the protein synthesis system. J. Biol. Chem. 264:2037-2042.

27. Hundal, H. S., M. J. Rennie, and P. W. Watt. 1987. Characteristics of L-glutamine transport in perfused rat skeletal muscle. J. Physiol. (Lond.). 393:283-305.

28. Hundal, H. S., M. J. Rennie, and P. W. Watt. 1989. Characteristics of acidic, basic and neutral amino acid transport in the perfused rat hindlimb. $J$. Physiol. (Lond.). 408:93-114.

29. Cobelli, C., M. P. Saccomani, E. Ferrannini, R. A. DeFronzo, R. Gelfand, and R. C. Bonadonna. 1989. A compartmental model to quantitate in vivo glucose transport in the human forearm. Am. J. Physiol. 257:E943-E958.

30. Andres, R., M. A. Baltzan, G. Cader, and K. L. Zierler. 1962. Effect of insulin on carbohydrate metabolism and on potassium in the forearm of man. $J$. Clin. Invest. 41:108-115.

31. Pozefsky, T. P., P. Felig, J. D. Tobin, J. Stuart-Soeldner, and G. F. Cahill. 1969. Amino acid balance across tissues of the forearm in postabsorptive man. Effects of insulin at two dose levels. J. Clin. Invest. 48:2273-2282.

32. Natali, A., G. Buzzigoli, S. Taddei, D. Santoro, M. Cerri, R. Pedrinelli, and E. Ferrannini. 1990. Effects of insulin on hemodynamics and metabolism in human forearm. Diabetes. 39:490-500.

33. Bassingthwaighte, J. B., and C. A. Goresky. 1984. Modeling in the analysis of solute and water exchange in the microvasculature. In Handbook of Physiology. The Cardiovascular System. Microcirculation. American Physiological Society, Bethesda, MD. 549-626.

34. National Diabetes Data Group. 1979. Classification and diagnosis of diabetes mellitus and other categories of glucose intolerance. Diabetes. 28:10391057.

35. Coles, D. R., K. E. Cooper, R. F. Mottram, and O. V. Occleshaw. 1958 The source of blood samples withdrawn from deep forearm veins via catheters passed upstream from the median cubital vein. J. Physiol. Lond. 142:258-267.

36. Somogyi, M. 1945. Determination of blood sugar. J. Biol. Chem. 160:6973.

37. Zierler, K. L. 1961. Theory of the use of arteriovenous concentration differences for measuring metabolism in steady and nonsteady state. J. Clin. Invest. 40:2111-2125.
38. Berman, M., W. F. Beltz, P. C. Gries, R. Chabay, and R. C. Boston 1983. CONSAM User's Guide. National Institute of Health, Bethesda, MD.

39. Berman, M., and M. F. Weiss. 1978. SAAM Manual. National Institutes of Health, Bethesda, MD. (Department of Health, Education and Welfare Publication No. 78-180).

40. Sorenson, J. A., and M. E. Phelps. 1987. Physics in Nuclear Medicine. 2nd ed. W.B. Saunders Co., Philadelphia, PA. 500-502. NJ.

41. Zar, J. Biostatistical Analysis. 1984. Prentice-Hall Inc., Englewood Cliffs,

42. Williams, I. H., P. H. Sugden, and H. E. Morgan. 1981. Use of aromatic amino acids as monitors of protein turnover. Am. J. Physiol. 249:E677-E681.

43. Barrett, E. J., and R. A. Gelfand. 1989. The in vivo study of cardiac and skeletal muscle protein turnover. Diabetes Metab. Rev. 5:133-148.

44. Barrett, E. J., J. Revkin, L. Young, B. Zaret, R. Jacob, and R. A. Gelfand 1987. An isotopic method for in vivo measurement of muscle protein synthesis and degradation. Biochem. J. 245:223-228.

45. Maroni, B. J., G. Karapanos, and W. Mitch. 1986. System A amino acid transport in incubated muscle: effects of insulin and acute uremia. Am. J. Physiol. 251:F74-F80.

46. Maroni, B. J., G. Kerapanos, and W. Mitch. 1986. System ASC and sodium-independent neutral amino acid transport in muscle of uremic rats. $\mathrm{Am}$. J. Physiol. 251:F81-F86.

47. Felig, P., T. Pozefsky, E. Marliss, and G. F. Cahill, Jr. 1970. Alanine: key role in gluconeogenesis. Science (Wash. DC). 167:1003-1004.

48. Storch, K. J., D. A. Wagner, J. F. Burke, and V. R. Young. 1988. Quantitative study in vivo of methionine cycle in humans using [ $\left.m e t h y l-{ }^{2} \mathrm{H}_{3}\right]-$ and $\left[1-{ }^{13} \mathrm{C}\right]$-methionine. Am. J. Physiol. 255:E322-E331.

49. Storch, K. J., D. A. Wagner, J. F. Burke, and V. R. Young. 1990. [ $1{ }^{13}$ C; methyl- ${ }^{2} \mathrm{H}_{3}$ ]-methionine kinetics in humans: methionine conservation and cystine sparing. Am. J. Physiol. 258:E790-E798.

50. Clausen, T. 1986. Regulation of active $\mathrm{Na}^{+}-\mathrm{K}^{+}$transport in skeletal muscle. Physiol. Rev. 66:542-580.

51. Christensen, H. N., D. L. Oxender, M. Liang, and K. A. Vatz. 1965. The use of $\mathrm{N}$-methylation to direct the route of mediated transport of amino acids. $J$ Biol. Chem. 240:3609-3616.

52. Zierler, K. L., and E. M. Rogus. 1981. Rapid hyperpolarization of rat skeletal muscle induced by insulin. Biochim. Biophys. Acta. 640:687-692.

53. Dawson, W. D., and T. C. Smith. 1987. Energetics of $\mathrm{Na}^{+}$-dependent amino acid co-transport in Ehrlich ascites tumor cells. Biochim. Biophys. Acta. 897:5-13.

54. Louard, R. J., E. J. Barrett, and R. A. Gelfand. 1990. Effect of infused branched-chain amino acids on muscle and whole-body amino acid metabolism in man. Cli. Sci. (Lond.). 79:457-466.

55. Bennett, W. M., A. A. Connacher, C. M. Scringeour, R. T. Jung, and M. J. Rennie. 1990. Euglycemic hyperinsulinemia augments amino acid uptake by human leg tissues during hyperaminoacidemia. Am. J. Physiol. 259:E185-E194. 